Reihe Geschichtswissenschaft Band 39 


\section{Die regierende Königin - Elizabeth I. von England}

Aspekte weiblicher Herrschaft im 16. Jahrhundert

Ursula Machoczek

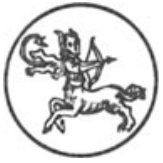

Centaurus Verlag \& Media UG 1996 
Die Autorin, Ursula Machoczek, ist Mitarbeiterin bei der Edition der deutschen Reichstagsakten jüngere Reihe - Historische Kommission der Bayrischen Akademie der Wissenschaften.

Die Deutsche Bibliothek - CIP-Einheitsaufnahme

\section{Machoczek, Ursula:}

Die regierende Königin - Elizabeth I. von England : Aspekte weiblicher Herrschaft im 16. Jahrhundert / Ursula Machoczek.

- Pfaffenweiler : Centaurus-Verl.-Ges., 1996

(Reihe Geschichtswissenschaft ; Bd. 39)

Zugl.: Heidelberg, Univ., Diss., 1994

ISBN 978-3-8255-0041-2

ISBN 978-3-86226-376-9 (eBook)

DOI 10.1007/978-3-86226-376-9

NE: GT

ISSN 0177-2767

Alle Rechte, insbesondere das Recht der Vervielfältigung und Verbreitung sowie der Übersetzung, vorbehalten. Kein Teil des Werkes darf in irgendeiner Form (durch Fotokopie, Mikrofilm oder ein anderes Verfahren) obne schriftliche Genebmigung des Verlages reproduziert oder unter Verwendung elektronischer Systeme verarbeitet, vervielfältigt oder verbreitet werden.

(C) CENTAURUS-Verlagsgesellschaft mit beschränkter Haftung, Pfaffenweiler 1996

Satz: Vorlage der Autorin 


\section{Danksagung}

Die vorliegende Arbeit wurde im Sommersemester 1994 von der Philosophisch-Historischen Fakultät der Universität Heidelberg als Dissertation angenommen und für die Drucklegung geringfügig überarbeitet. Mein besonderer Dank gilt meinem Doktorvater und Lehrer, Herrn Professor Dr. Eike Wolgast, der das Entstehen dieser Untersuchung mit großem Interesse verfolgte und auf vielfältige Weise förderte. Herr Professor Dr. Volker Sellin übernahm dankenswerterweise das Korreferat. Während meiner Archivarbeiten in London fand ich offene Aufnahme am Institute of Historical Research. Dr. Lyndal Roper und Dr. Jinty Nelson haben während dieser Zeit den Entwicklungsgang meiner Arbeit durch zahlreiche anregende Diskussionen gefördert. Mein Dank gilt ebenso den Mitarbeitern der British Library und des Public Record Office für ihre freundliche und effiziente Kooperation. Der DAAD ermöglichte durch ein Stipendium die furr meine Untersuchung grundlegenden, umfangreichen Archivstudien in Großbritannien. Darüber hinaus wurde die Verwirklichung meines Arbeitsvorhabens durch die Unterstützung der Landesgraduiertenförderung erleichtert. Neben Anregungen und Hilfe von akademischer Seite wäre der erfolgreiche Abschluß meiner Dissertation ohne den Beistand meiner Familie und meiner Freunde undenkbar gewesen. Mein Dank gilt Thomas Arens furr die Erstellung der Schaubilder und der Druckvorlage sowie Petra Konrad, Susanne Kühn und Kirsten Burmeister für ihre unermüdliche Diskussionsbereitschaft und die Übernahme der Sisyphusarbeit des Korrekturlesens. Ihnen allen möchte ich für die Motivierung danken, ganz besonders aber meinen Eltern, die mir den Weg des Studiums und der Promotion ermöglichten. 


\section{Inhalt}

I. Einleitung

1. Das Phänomen der regierenden Frau im 16. Jahrhundert 1

1.1. Problemstellung 1

1.2. Quellenlage 7

1.3. Forschungsstand 9

2. Der ideengeschichtliche Kontext weiblicher Herrschaft im 16. $\begin{array}{ll}\text { Jahrhundert } & 13\end{array}$

2.1. Herrschaft und Herrscher in englischen Staatstheorien 13

$\begin{array}{ll}\text { Stellung und Aufgaben des Souveräns } & 13\end{array}$

$\begin{array}{ll}\text { Fürstenideal und Herrschertugenden } & 19\end{array}$

2.2. Das Bild der weiblichen Natur und seine Auswirkungen auf die Stellung der Frau in der Gesellschaft $\quad 25$

Biologische und theologische Definition der weiblichen Natur 25

Die Stellung der Frau in Ehe und Staat $\quad 29$

Weibliche Tugenden und Erziehung $\quad 35$

2.3. Frau und Herrschaft? 41

II. Bedingungen weiblicher Herrschaftsausübung 43

1. Erziehung 43

1.1. Theorie und Praxis der Ausbildung von Tudor-Prinzen 44

Pädagogische Schriften zur Prinzenerziehung 44

Die Ausbildung von Tudor-Prinzen $\quad 52$

Arthur und Henry VIII. $\quad 53$

$\begin{array}{ll}\text { Edward VI. } & 58\end{array}$

1.2. Theorie und Praxis der Ausbildung von Tudor-Prinzessinnen 62

Pädagogische Schriften zur Prinzessinnenerziehung 62

Die Ausbildung von Tudor-Prinzessinnen $\quad 69$

$\begin{array}{ll}\text { Margaret und Mary Tudor } & 72\end{array}$

$\begin{array}{ll}\text { Mary I. } & 74\end{array}$

Jane Grey und Elizabeth I. $\quad 77$

1.3. Elizabeths I. Erziehung als Bedingung weiblicher

$\begin{array}{ll}\text { Herrschaftsausübung } & 83\end{array}$

1.4. Elizabeths I. nachgeholte Prinzenerziehung 85

2. Das Phänomen weiblicher Autoritätsausübung 92

2.1. Die zeitgenössische Debatte über weibliche Herrschaft 93

"The Monstruous Regiment of Women" - die Gegner 95

Thomas Becon und Christopher Goodman 95

$\begin{array}{ll}\text { John Knox } & 98\end{array}$ 
"An Harborowe for Faithfvll and Trewe Svbiectes" - die

Befürworter

John Aylmer und John Jewel 106

John Leslie

2.2. Historische Präzedenzfälle

Formen inoffizieller politischer Aktivität

Präzedenzfälle weiblicher Herrschaft in England vor dem

Regierungsantritt Elizabeths I.

Vorgeschichte

Regentinnen

129

Die erste Herrscherin

134

Das Image weiblicher Herrschaftsausübung

139

2.3. Die Situation zum Zeitpunkt von Elizabeths I. Regierungsantritt

3. Eheschließung

3.1. Ideelle und rechtliche Problematik der Eheschließung des weiblichen Souveräns

3.2. Theoretische Lösungsversuche 149

3.3. Historische Präzedenzfälle 152

Der Ehevertrag Marys I. $\quad 152$

Die Ehen Jane Greys und Mary Stuarts 161

Die Forderungen der Ehekandidaten Elizabeths I. 169

3.4. Elizabeth I. als Herrscherin und Ehefrau? 172

III. Elizabeth I. - das Selbstverständnis der regierenden Frau 175

1. Elizabeths I. Parlamentsrhetorik 175

1.1. Politische Bedeutung der Parlamentsreden 175

1.2. Chronologie und Inhalt der Parlamentsreden 179

$\begin{array}{ll}\text { Politische Rechenschaftsberichte } & 179\end{array}$

Eheschließung und Thronfolgeproblematik 193

Religion $\quad 209$

Mary Stuart 214

1.3. Elizabeths I. Redeverhalten - Zusammenfassung 219

2. Elizabeths I. Selbstdarstellung als regierende Frau 223

2.1. Herrschaftsverständnis und Machtlegitimierung 223

$\begin{array}{ll}\text { 2.2. Verwendung von Herrschertugenden im Rahmen der } & \\ \text { Selbstinszenierung als weiblicher Souverän } & 239\end{array}$

$\begin{array}{ll}\text { Sapientia } & 239\end{array}$

Magnanimitas 251

$\begin{array}{ll}\text { Justitia } & 259\end{array}$

Fortitudo 266

Temperantia 273 
2.3. Charakteristica des weiblichen Souveräns 277

Vorstellungen von Natur und Wesen der Frau 277

Weibliche Tugenden und die Bestimmung der Frau 282

Elizabeth I. als Mutter ihrer Untertanen 289

Die Verwendung der Ehesymbolik bei Elizabeth I. 296

Herrschaft als mystische Liebesbeziehung 301

2.4. Männliche Formen der Selbstinszenierung 305

Exkurs: Elizabeths I. Selbstinszenierung vor dem Fachpublikum von Oxford und Cambridge $\quad 308$

a) Formale Aspekte 309

b) Inhaltliche Aspekte 311

3. Die Gebete Elizabeths I. 319

3.1. Chronologie und Kontext der Gebete 320

3.2. Herrschaftsverständnis und Machtlegitimierung 323

3.3. Verwendung von Herrschertugenden 333

3.4. Natur und Wesen der Frau 338

3.5. Weibliche Definitionsmuster 340

4. "She was more than a man, and, in troth, sometimes less than a woman" - Zusammenfassung

IV. Elizabeth I. - das Fremdverständnis der regierenden Frau

1. Konzeptionen des weiblichen Souveräns in Äußerungen der machtbeteiligten Schicht männlicher Untertanen 355

1.1. Petitionen und Pamphlete zum Problem der Eheschließung 355

Ehepetitionen des Parlaments $\quad 360$

Argumente fur eine Eheschließung der persona publica 360

Argumente fur eine Eheschließung der persona privata $\quad 366$

Inoffizielle Ehepetitionen $\quad 369$

Argumente für eine Eheschließung der persona publica 369

Argumente fur eine Eheschließung der persona privata $\quad 379$

Inoffizielle Eheablehnungen 383

Gründe gegen eine Heirat der persona publica 383

Gründe gegen eine Heirat der persona privata 390

Elizabeth I. als weiblicher Souverän im Rahmen der Ehediskussion -

Zusammenfassung

1.2. "What, cannot princes err?"- kritische Stimmen zu Elizabeths I.

Verhalten als Souverän $\quad 394$

Peter Wentworth 397

Stellung und Verantwortung des Souveräns 397

Elizabeths I. Fehlverhalten und dessen Ursachen 401 
Robert Devereux, Earl of Essex 406

Stellung des Souveräns $\quad 406$

Elizabeths I. Fehlverhalten 408

Elizabeth I. als Souverän im Spiegel politischer Kritik -

Zusammenfassung

2. "My loving people"? - Konzeptionen des weiblichen Souveräns auf der Ebene machtunbeteiligter Untertanen

2.1. Reden und Pageantry zu Ehren königlicher Stadtbesuche 412

Konzeptionen des weiblichen Souveräns in Festreden 415

Herrschaftsbilder und Machtlegitimierung 415

Herrschertugenden $\quad 423$

Herrschaftsqualitäten $\quad 430$

Darstellungsformen der regierenden Frau im Rahmen der Pageantry 435

Elizabeth I. als protestantischer Souverän $\quad 436$

Elizabeth I. als idealisierte Frau 442

Die positive Konzeption des Souveräns im Rahmen der

Stadtempfänge - Zusammenfassung 445

2.2. Majestätsbeleidigungs- und Hochverratsprozesse in den

Verhandlungen der Assise-Gerichte 1558 - 1603

Quantitative Analyse $\quad 450$

Qualitative Analyse $\quad 454$

Kritische Stellungnahmen zur Machtposition des Souveräns $\quad 454$

Negative Herrschereigenschaften und Herrschaftsqualitäten 458

Negative Qualitäten weiblicher Herrschaft 461

Negative Eigenschaften der regierenden Frau 463

Negative Konzeptionen des wẹiblichen Souveräns -
Zusammenfassung

3. Darstellungen des weiblichen Souveräns im posthumen

Fremdverständnis $\quad 466$

3.1. Grabinschrift und Nachrufe 468

Elizabeth I. als Souverän $\quad 468$

Elizabeth I. als Frau $\quad 475$

3.2. William Camdens Annalen 478

3.3. Die retrospektive Bewertung Elizabeths I. als weiblicher Souverän Zusammenfassung

\section{Schluß}

Anhang

Stammbaum 492

Chronologie und Inhalt der Parlamentsreden Elizabeths I. 493

Fälle von Majestätsbeleidigung und Hochverrat 1558 - 1603 
Abkürzungen und Zeichenerklärung

Bibliographie 496

Unedierte Quellen

496

Edierte Quellen

497

Literatur

504 